\title{
AA-6082 T4 Alaşımının Tornalamasında Çok Kristalli Elmas (ÇKE) Takımlara Uygulanan Talaş Kırıcı Formlarının Kesme Kuvvetleri Üzerindeki Etkilerinin Araştırılması

\author{
Selçuk YAĞMUR ${ }^{*}$, $\mathbb{D}$, Müzeyyen Kübra KAYA ${ }^{\text {b, }}$ (D), Ulvi ŞEKER ${ }^{\mathrm{a}}$ \\ a,* Gazi Üniversitesi Teknoloji Fakültesi İmalat Mühendisliği Bölümü, Ankara, Türkiye. \\ ${ }^{b}$ Gazi Üniversitesi Fen Bilimleri Enstitüsü, Ankara, Türkiye.
}

MAKALE

BİLGISI

Alınma: 19.03.2021

Kabul: 21.04 .2021

\section{Anahtar Kelimeler:}

Cok Kristalli Elmas

(ÇKE), Talaş Kırıcı,

AA6082, Tornalama

\section{$\ddot{O} \mathbf{Z}$}

\begin{abstract}
Alüminyum alaşımlarının çeliklere oranla daha düşük yoğunluğa sahip olması ile birlikte alaşımlandırma gibi işlemler ile çeliklere yakın dayanıma sahip olmaları sayesinde, havacılık sanayi başta olmak üzere pek çok alanda yaygın olarak kullanılmaktadır. Fakat bu önemli avantajının yanında işleme zorluklarının olması alüminyum alaşımlarının işlenmesinde bazı sorunlar doğurmuştur. Sürekli talaş oluşumu ve yığıntı talaş bu sorunların başında gelmektedir. Özellikle sürekli talaş oluşumu neticesinde malzemeye sarılan talaşın yeniden kesilmesi ile birlikte kesme kuvvetlerin arttığı bilinmektedir. Bu çalışmada sürekli talaş oluşumu engellemek amaciyla talaş kırıcı formu uygulanmış çok kristalli elmas takımlar ile AA 6082 T4 alaşımının tornalamasında meydana gelen kesme kuvvetleri araştııılmıştır. Çalışmada lazer bileme yöntemiyle farklı talaş kırıcı formları oluşturulmuş çok kristalli elmas (ÇKE) takımlar ve talaş kırıcısız ÇKE takımlar kullanılmıştır. Takımların uç yarıçapları 0.4 ve 0.8 mm'dir. Kesme parametreleri olarak $0.14 \mathrm{~mm} / \mathrm{dev}$ sabit ilerleme miktarı, iki farklı kesme hızı (200 ve $400 \mathrm{~m} / \mathrm{dak})$ ve altı farklı kesme derinliği $(0.02,0.06,0.1,0.14,0.20$ ve $0.26 \mathrm{~mm})$ belirlenmiştir. Çalışma neticesinde en düşük kesme kuvvetleri değerlerine talaş kırıcılı takımlar ile yapılan deneylerde ulaşıldı̆̆ görülmüştür.
\end{abstract}

https://dx.doi.org/10.30855/gmbd.2021.01.06

\section{Investigation of the Effects of Chip Breaker Forms Applied to Polycrystalline Diamond (PCD) Tools on Cutting Forces in Turning AA- 6082 T4 Alloy}

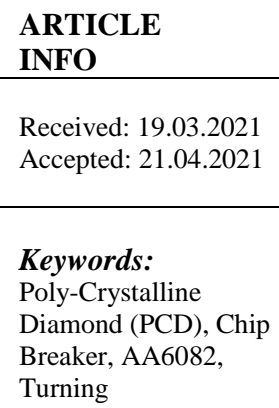

\begin{abstract}
Aluminum alloys have lower density compared to steels, and their strength close to steels through processes such as alloying has enabled them to be widely used in many areas, especially in the aviation industry. However, besides this important advantage, machining difficulties have created some problems in the processing of aluminum alloys. Continuous chip formation and built up edge (BUE) are the main problems. It is known that the cutting forces increase with the re-cutting of the chips that are wrapped in the material as a result of continuous chip formation. In this study, the cutting forces occurring during turning of AA $6082 \mathrm{~T} 4$ alloy with polycrystalline diamond tools applied in chip breaker form to prevent continuous chip formation were investigated. In the study, different chip breaker forms were formed by laser sharpening PCD tools and PCD tools without breakers were used. Cutting tools have two differents tip radius $(0.4$ and $0.8 \mathrm{~mm})$. As cutting parameters, $0.14 \mathrm{~mm} / \mathrm{rev}$ constant feed rate, two different cutting speeds (200 and 400 $\mathrm{m} / \mathrm{min})$ and six different cutting depths $(0.02,0.06,0.1,0.14,0.20$ and $0.26 \mathrm{~mm})$ were determined. As a result of the study, it was seen that the lowest cutting force values were reached in the experiments with the breaker tools.
\end{abstract}




\section{GIRISŞ (INTRODUCTION)}

Hafif metaller, özellikle alüminyum ve magnezyum alaşımları yüksek mukavemet, düşük yoğunluk ve kolay üretim gibi özelliklerinden dolayı elektronik, genel mühendislik ve havacıllk endüstrilerinde kullanılmaktadır [1]. Birçok alüminyum alaşımı, yüksek kesme hızlarında işlendiğinde, iyi yüzey kalitesi ve uzun takım ömrü sağlamaktadır. Genellikle, sertleştirilmiş ve temperlenmiş alaşımlar tavlanmış alaşımlardan daha kolay işlenir ve daha iyi kalitede yüzey meydana getirirler. Silisyum içeren alaşımları işlemek daha zordur, bunun sebebi talaş kaymadan yırtılır ve bundan dolayı düşük yüzey kalitesi elde edilir [2]. Alüminyum alaşımlarının endüstride yaygın olarak kullanılmasıyla beraber bu alaşımların işlenmesinde yaşanan sorunlar ortaya çıkmaya başlamıştır. $\mathrm{Bu}$ sorunlar neticesinde araştırmacıların alüminyumun işlenebilirliği ile ilgili çalışmalarına literatürde sıklıkla rastlamak mümkün olmuştur. Agustina ve arkadaşları UNS A9707 alüminyum alaşımının kuru tornalamasında meydana gelen kesme kuvvetlerini incelemiştir. Çalışma sonrasında en etkili faktörlerin sırasıyla ilerleme miktarı, kesme derinliği, kesici takım tipi ve devir sayısı olduğu sonucuna ulaşmışlardır [3]. Sekmen ve arkadaşları kesme hızı ve talaş açısının alüminyum alaşımlarının işlenmesinde yüzey pürüzlülüğü, yığıntı talaş oluşumu üzerine etkisini araştırmışlardır. Çalışma sonrasında AA 7075 alaşımında, AA 2011 alaşımına göre daha fazla yığıntı katman ve Yı̆̆ıntı talaş oluştuğu sonucuna ulaşmışlarıdır [4]. Bayraktar ve Turgut çalışmalarında AL-5083 alaşımının frezelenmesinde kesme kuvveti, yüzey pürüzlülüğü ve çapak yüksekliğinin optimizasyonunu araştırmışlardır. Çalışmada ilerleme parametresinin, kesme kuvveti, yüzey pürüzlülüğü ve çapak yüksekliği üzerinde en etkili faktör olduğu sonucuna ulaşmışlardır [5]. Akyüz ve Şenaysoy alüminyum alaşımlarında yaşlandırma işleminin işlenebilirlik üzerindeki etkilerini araştırmışlardır. Yaşlandırma süresinin artmasına bağlı olarak alaşımların işlenmesi sırasında oluşan kesme kuvvetlerinde artış görüldüğü sonucuna ulaşmışlardır [6]. Bu çalışmalar ile birlikte optimisazyon ve modelleme gibi çalışmalara da literatürde rastlamak mümkündür [7-12]. Ayrıca farklı soğutma şartlarının alüminyum alaşımlarının işlenebilirliğine etkileri de literatürde görülebilmekte. Çakır ve arkadaşları soğutma şartları ve kesme parametrelerinin AA7075 ve AA2024 alüminyum alaşımlarının delinmesindeki etkilerini deneysel olarak incelemişlerdir. Artan ilerleme oranlarının ilerleme kuvvetlerini arttırdığı sonucuna ulaşmışlardır [13]. Çakır ve arkadaşları AA7075 ve AA2024 alüminyum alaşımlarının tornalanmasında farklı parametreler altında minimum miktarda yağlamanın etkisini deneysel olarak incelemişlerdir. Deneyler sonrasında MQL kullanımının işlenebilirlik açısından olumlu bir etki yaptığı sonucuna varmışlardır [14]. Cönger ve arkadaşları alüminyum 6061 malzemenin MQL yöntemi ile frezelenmesinde Nano MoS2 katkılı kesme sıvısı kullanımının kesme kuvvetleri ve yüzey pürüzlülüğüne etkilerini incelemişler. Çalışma sonucunda, MQL yönteminde yüksek debide nano akışkanın kesme kuvvetlerini ve yüzey pürüzlülüğünü olumlu etkilediği sonucuna ulaşmışlardır [15].

Yapılan literatür araştırması neticesinde, AA 6082 T4 isıl işlemi uygulanmış malzeme ile ilgili çalışmaların sayısı oldukça az olduğu görülmüştür. Ayrıca İmalat sektöründe ÇKE takımlara talaş kırıcı uygulanması yeni bir uygulama olup talaş kırıcılı ÇKE takım ile işleme konusunda ise daha önce yapılmış olan herhangi bir çalışmaya rastlanmamıştır. $\mathrm{Bu}$ çalışmada ÇKE kesici takımlara uygulanan talaş kırıcıların kesme kuvvetlerine etkisi AA 6082 T4 malzeme üzerinde yapılan deneylerle birlikte incelenmiştir.

\section{MATERYAL VE METOD (MATERIAL AND METHOD)}

Bu çalışmada deney malzemesi olarak AA 6082 T4 alaşımı kullanılmıştır. Numuneler $100 \mathrm{~mm}$ çapında $170 \mathrm{~mm}$ boyunda hazırlanmıştır.

İşlenebilirlik deneylerinde kullanılan kesici takımlar DTS GmbH (Almanya) takım firması tarafından lazer bileme yöntemiyle farklı talaş kırıcı geometrilerine sahip olarak üretilmiştir. Kesici takımların görüntüleri Tablo 1'de toplu halde verilmiştir. Uç yarıçapı $0.4 \mathrm{~mm}$ olan talaş kırıcılı ve talaş kırıcısız takımlar 308 FN, 304 SPL-P, 304 SPL$\mathrm{N}$ olarak $0.8 \mathrm{~mm}$ uç yarıçaplı talaş kırıcılı ve talaş kırıcısız takımlar ise 308 FN, 308 SPL- P, 308 SPL$\mathrm{N}$ şeklinde kodlanmıştır. FN kodlu takımlar talaş kırıcısız takımları ifade ederken SPL-P ve SPL-N kodlu takımlar ise talaş kırıcılı takımları ifade etmektedir.

Kesme parametreleri, takım üretici firmanın (DTS $\mathrm{GmbH})$ önerdiği değerler esas alınarak özellikle belirlenmiştir. Kesme derinlikleri kesici takım uç yarıçaplarından düşük olarak seçilmiştir. Bu durum kesici takım üretici firmasının isteği doğrultusunda 
gerçekleşmiş̧ir. Çalışmada kullanılan kesme parametreleri Tablo 2'de verilmiştir. İşlenebilirlik deneyleri Gazi Üniversitesi Teknoloji Fakültesi İmalat Mühendisliği Bölümünde yapılmıştır. Deneylerde, “Johnford TC-35" sanayi tipi
CNC torna tezgâhı kullanılmıştır. Kesme kuvvetlerinin ölçümü için KISTLER 9257 dinamometre ve Kistler Type 5070 yükseltici kullanılmıştır.

Tablo 1. Deneylerde kullanılan kesici takımlar (Cutting tools used in the experiments)

\begin{tabular}{|c|c|c|}
\hline FN (Kiricisiz) & \\
\hline SPL-P & 304 & 308 \\
\hline SPL-N & & \\
\hline
\end{tabular}

Tablo 2. Deneylerde kullanılan kesme parametreleri (Cutting parameters used in the experiments)

\begin{tabular}{|c|c|c|}
\hline İlerleme Miktarı (mm/dev) & Kesme Hızı (m/dak) & Talaş Derinliğ (mm) \\
\hline \multirow{3}{*}{0.14} & & 0.02 \\
& 200 & 0.06 \\
& 400 & 0.10 \\
& & 0.14 \\
& & 0.20 \\
& & 0.26 \\
\hline
\end{tabular}

\section{DENEY SONUÇLARI VE TARTIŞMA (EXPERIMENTAL RESULTS AND DISCUSSION)}

Deneyler sonrasinda elde edilen kesme kuvvetleri değerlerinin 0,4 mm kesici takım uç yarıçapına sahip (304) takımlar ile yapilan deneylerde kesme derinliğine göre değişimini gösteren grafik Şekil 1'de verilmiştir.

Şekil 1a'daki grafikte, $200 \mathrm{~m} /$ dak sabit kesme hızında $0.4 \mathrm{~mm}$ kesici takım uç yarıçapına sahip takımlarda genel olarak en yüksek kesme kuvvetlerinin talaş kırıcısız takımlarla yapılan deneylerde elde edildiği görülmektedir. Bununla

birlikte en düşük kesme kuvvetlerinin ise talaş kırıcı formuna sahip SPL-N kodlu takımlarla yapılan deneylerde elde edildiği sonucuna ulaşılmıştır.
İstisnalar haricinde kesme derinliğinin artması sonucunda kesme kuvvetleri de artmıştır [16]. Kesme derinliğinin artması kesilen talaş hacminin artmasına sebep olduğundan kesme kuvvetlerini de arttırmıştır. Ayrıca artan kesme derinliği ile birlikte talaş kırıcılı takımlar ile elde edilen kesme kuvvetlerinin talaş kırıcısız takımlarla elde edilen değerlere yaklaştığ görülmektedir. Şekil 2'de verilen talaş resimleri incelendiğinde artan kesme derinliği neticesinde talaş kırıcı formuna sahip SPL-P kodlu takımda talaşların kırılamadığı gözlenmiştir. Talaş biçimlerinden görüleceği gibi, artan kesme derinlikleri ile kırılamayan talaş deney numunesine sarılma eğilimi göstermiş ve bu da talaşın yeniden kesilmesine sebep olarak kesme kuvvetlerinin artmasına yol açmıştır. Kesici takımlara uygulanan talaş kırıcı formlarının kesme kuvvetlerini olumlu yönde etkilediği literatürde karş1laşılan bir durumdur [17-19]. Talaş 
kırıcısız takımlar ile yapılan deneylerde meydana gelen talaş biçimleri Şekil 3 'te verilmiştir.

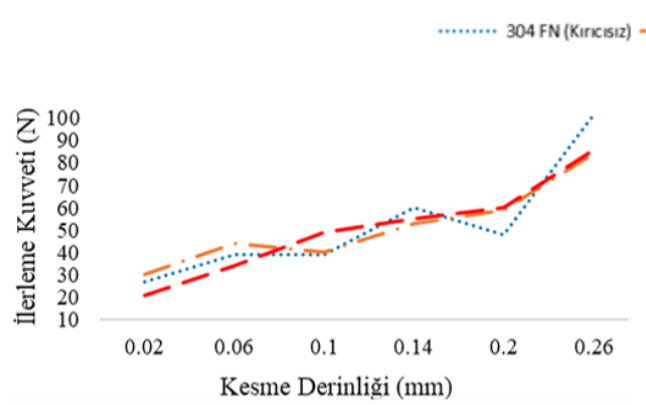

a)

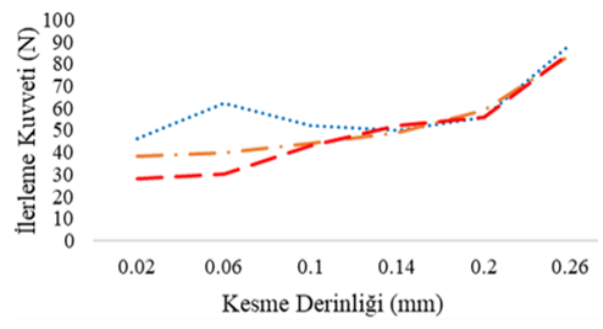

b)

Şekil 1. $0.4 \mathrm{~mm}$ kesici takım uç yarıçapında talaş derinliğine bağlı ilerleme kuvveti değişimi a) $200 \mathrm{~m} / \mathrm{dak}$

b) $400 \mathrm{~m} / \mathrm{dak}$ (Cutting force variation depending on depth of cut at $0.4 \mathrm{~mm}$ cutting tool radius a) $200 \mathrm{~m} / \mathrm{min} \mathrm{b}$ ) $400 \mathrm{~m} / \mathrm{min}$ )

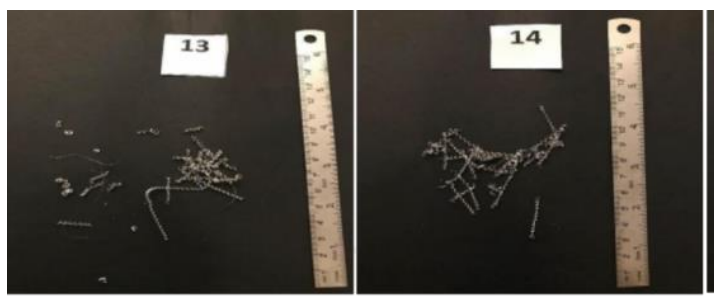

(b)

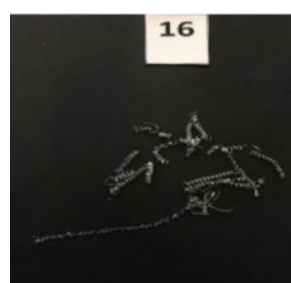

(d)

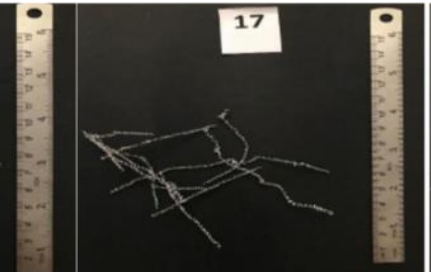

(e)

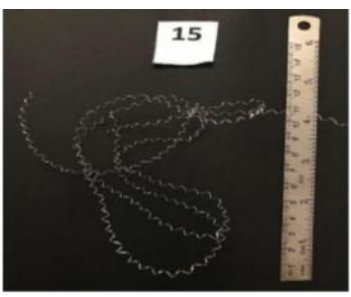

(c)

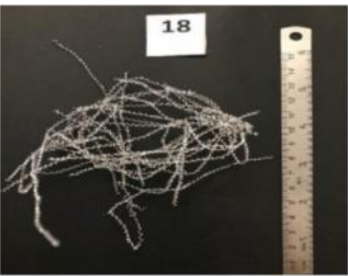

$(f)$

Şekil 2. $200 \mathrm{~m}$ /dak kesme hızında SPL-P kodlu talaş kırıcılı takımda kesme derinliğine göre oluşan talaş

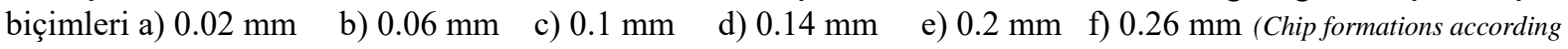
to cutting depth in SPL-P coded with chip breaker tool at $200 \mathrm{~m} /$ min cutting)

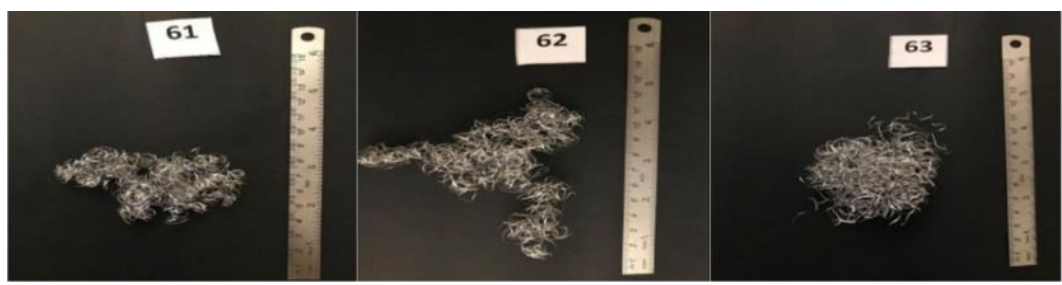

(a)

(b)

(c)

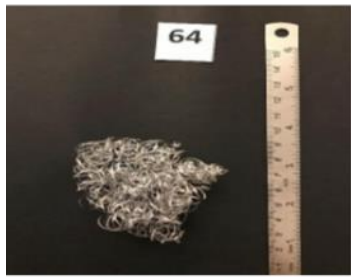

(d)

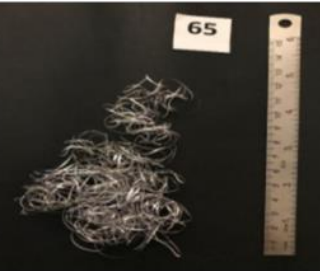

(e)

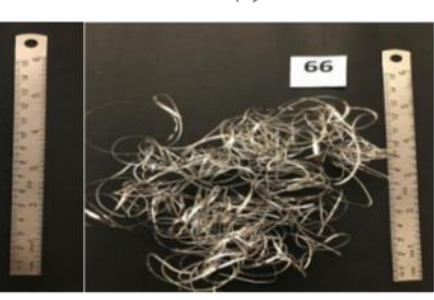

(f)

Şekil $3.200 \mathrm{~m}$ /dak kesme hızında FN kodlu talaş kırıcısız takımda kesme derinliğine göre oluşan talaş

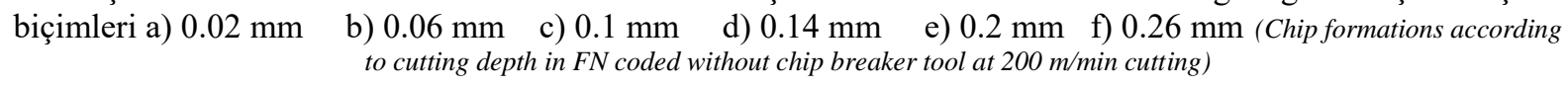


Kesme hızının 200 m/dak'dan 400 m/dak'a çıkması genel olarak kesme kuvvetlerinde düşüşe sebep olmuştur (Şekil 1b). Artan kesme hılarında kesme kuvvetlerindeki düşüş beklenen bir durumdur ve bu durum literatüratürle benzerlik arz etmektedir. [20-22]. Artan kesme hizlarının kesme bölgesindeki sicaklığını arttırdığ 1 bilinmektedir [23]. Kesme bölgesindeki sıcaklığın artması, kesme işlemini nispeten kolaylaştırdığı ve kesme kuvvetlerinin düşmesine yol açtığı düşünülmektedir. Artan kesme hızları ile birlikte kesme kuvvetlerinin düşmesi literatürde karşılaşılan bir durumdur [24-26]. Fakat talaş kırıcısız takımda $0.26 \mathrm{~mm}$ kesme derinliğinde $200 \mathrm{~m} /$ dak kesme hızına göre kesme kuvvetlerinde bir artış gözlemlenmiştir. Bu durum artan kesme derinliği neticesinde talaşın kırılmayarak yeniden kesilmesine atfedilmiştir (Şekil 3).

$0.8 \mathrm{~mm}$ uç yarıçapına sahip kesici takımlarla yapılan deneylerde elde edilen kesme kuvvetleri incelendiğinde; genel eğilimin 0.4 uç yarıçapına sahip kesicilerdeki gibi olduğu görülmektedir.

Şekil 4a'daki grafikte $0.8 \mathrm{~mm}$ uç yarıçapına sahip kesici takımlarda (308) meydana gelen kesme kuvvetlerinin $200 \mathrm{~m} /$ dak kesme hizında kesme derinliğine bağlı olarak değişimi verilmiştir. Grafikte, artan kesme derinliklerinin kesme kuvvetlerini arttırdığı görülmektedir. $\mathrm{Bu}$ durum $0.4 \mathrm{~mm}$ uç yarıçapına sahip takımlarda olduğu gibi kırılamayan talaşların yeniden kesilmesine atfedilmiştir. Grafikte, talaş kırıcısız takım ve SPL-N kodlu talaş kırıcı formuna sahip takımları ile elde edilen kesme kuvvetleri değerlerinin birbirine oldukça yakın olduğu görülmektedir. Her ne kadar bu iki takım arasındaki fark oldukça küçük olsa da $0.4 \mathrm{~mm}$ kesici takım uç yarıçapına sahip takımlarda olduğu gibi en düşük kesme kuvvetlerinin talaş kırıcısız takımlar ile yapılan deneylerde elde edildiği görülmektedir. SPL-P kodlu talaş kırıcı formuna sahip takımlar ile yapılan deneylerde elde edilen değerlerin diğer iki takıma oranla oldukça düşük gerçekleştiği grafikten görülebileceği (Şekil 4a) gibi $0.26 \mathrm{~mm}$ kesme derinliğinde bu üç takımla elde edilen değerlerin birbirine oldukça yaklaşmaktadır.

Benzer bir durum Şekil 4b'de verilen grafikte de mevcuttur. Grafikte 400 m/dak kesme hızında 0.8 uç yarıçapına sahip kesiciler ile yapılan deneylerde kesme kuvveti değişimi gösterilmiştir.

Özelikle düşük kesme derinliklerinde, uç yarıçapının artması, kesme kuvvetlerinde artışa sebep olomuştur. Bu durum $400 \mathrm{~m} /$ dak kesme hızında daha belirgin olarak meydana gelmiștir. Takım uç yarıçapı ile birlikte kesme kuvvetlerinin artması literatürde karşılaşılan bir durumdur [27, 28]. Kesici takımda oluşan bileşke kuvvetin, talaş yüzeyinde oluşan kesme kuvveti ile kesici takım uç yarıçapı etkisiyle oluşan kuvvetin bileşkesi olduğundan uç yarıçapının artması kuvvetleri de arttırmıştır. [29]. $400 \mathrm{~m} /$ dak kesme hızında 0.4 uç yarıçapına sahip takımlarda olduğu gibi en düşük kesme kuvvetlerinin talaş kırıcısız takımlar ile yapılan deneylerde elde edildiği görülmektedir. SPL-P kodlu talaş kırıcı formuna sahip takımlar ile yapılan deneylerde, $0.02 \mathrm{~mm}$ ve $0.06 \mathrm{~mm}$ kesme derinliklerinde elde edilen kuvvet değerleri diğer iki takıma göre daha düşük gerçekleşmiştir. Grafikten görülebileceği gibi (Şekil 4b) $0.1 \mathrm{~mm}$ kesme derinliğinden sonra kuvvetlerde artış başlamış ve 0.26 $\mathrm{mm}$ kesme derinliğinde her üç takımla elde edilen kuvvet değerleri birbirine oldukça yaklaşmıştır.

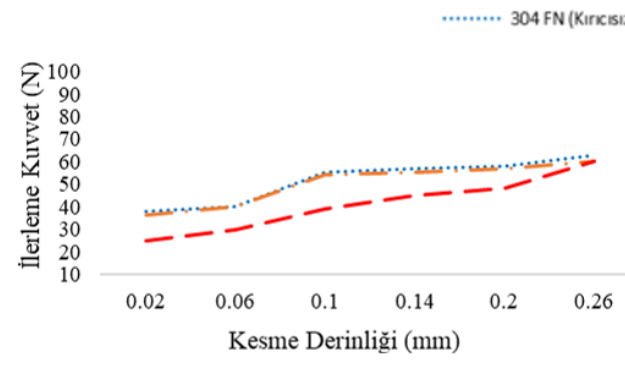

a)

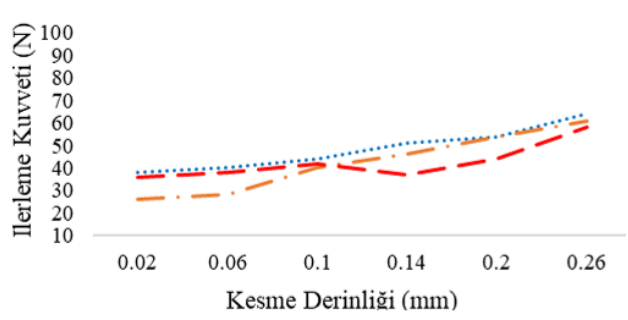

b)

Şekil 4. $0.8 \mathrm{~mm}$ kesici takım uç yarıçapında talaş derinliğine bağlı ilerleme kuvveti değişimi a) $200 \mathrm{~m} / \mathrm{dak}$

b) $400 \mathrm{~m} / \mathrm{dak}$ (Cutting force variation depending on depth of cut at $0.8 \mathrm{~mm}$ cutting tool radius a) $200 \mathrm{~m} / \mathrm{min} \mathrm{b}$ ) $400 \mathrm{~m} / \mathrm{min}$ )

Talaş kırıcısız takımlar ile yapılan deneylerde, artan kesme derinliklerinin her iki uç yarıçapına sahip kesici takımlarda kesme kuvvetlerini arttırdığı görülmektedir. Talaş derinliği uç yarıçapı ilişkisi neticesinde en düşük kesme kuvvetleri $0.8 \mathrm{~mm}$ uç yarıçapına sahip takımlarla yapılan deneylerde meydana gelmiştir. Her ne kadar talaş kırıcı formları beklenen sonucu vermese de en düşük kesme kuvvetleri talaş kırıcılı SPL-N, SPL-P kodlu takımlarda görülmüştür. En yüksek kesme 
kuvvetlerinin ise kırıcısız FN kodlu takımda meydana gelmesi, talaş kırıcı formlarının kesme kuvvetlerini olumlu etkilediğini göstermektedir.

\section{SONUÇLAR (RESULTS)}

Bu çalışmada AA 6082 T4 malzemesinin talaş kırıcı formuna sahip olan ve talaş kırıcı formuna sahip olmayan takımlar ile tornalanması sonucunda aşağıdaki bulgulara ulaşılmıştır.

- İstisnalar haricinde genel olarak bütün takımlarda kesme derinliğinin artması sonucunda kesme kuvvetleri de artmıştır.

- En düşük kesme kuvveti 0.4 uç yarıçapına sahip SPL-N kodlu takımda $400 \mathrm{~m} /$ dak kesme hızında $0.26 \mathrm{~mm}$ kesme derinliğinde meydana gelmiştir.

- En yüksek kesme kuvveti 304 FN kodlu (talaş kırıcısız) $0.4 \mathrm{~mm}$ uç yarıçapına sahip takımda $400 \mathrm{~m} /$ dak kesme hızında $0.26 \mathrm{~mm}$ kesme derinliğinde meydana gelmiştir.

- Artan kesme hızlarının literatüre paralel bir şekilde kesme kuvvetlerinde düşüşe yol açtığ 1 gözlemlenmiştir.

- Talaş talaş kırıcılı ve talaş kırıcısız takımlarda kesme derinliği arttıkça kesme kuvvetleri değerleri birbirine yaklaşmıştır.

- Talaş kırıcı formuna sahip takımlarla yapılan deneylerde meydana gelen kesme kuvvetlerinin daha düzenli bir eğilim sergilediği görülmüştür.

\section{ÇIKAR ÇATIŞMASI BİLDIRIMI (CONFLICT OF INTEREST STATEMENT)}

Yazarlar tarafından herhangi bir çıkar çatışması bildirilmemiştir.

\section{KAYNAKLAR (REFERENCES)}

[1] F.C. Walsh, C.T.J. Low, R.J.K. Wood, K.T. Stevens, J. Archer, A. R. Poeton, A. Ryder, "Plasma electrolytic oxidation (PEO) for production of anodised coatings on lightweight metal ( $\mathrm{Al}, \mathrm{Mg}, \mathrm{Ti}$ ) Alloys" A review, Transactions of the Institute of Metal Finishing, vol. 87, pp. 122-135, 2009. doi: https://doi.org/10.1179/174591908X372482

[2] Y. Şahin, Talaş Kaldırma Prensipleri 2. Ankara, Nobel Yayın Dağıtım, 2001

[3] B. Agustina, C.Bernal, A.M.Camacho, E.M.Rubio, "Experimental analysis of the cutting forces obtained in dry turning processes of UNS A97075 aluminium alloys" Procedia Engineering, vol. 63, pp 694-699, 2013. doi:https://doi.org/10.1016/j.proeng.2013.08.248

[4] M. Sekmen, M. Günay, U. Şeker, "alüminyum alaşimlarinin işlenmesinde kesme hizi ve talaş açisinin yüzey pürüzlülüğü, yiğıntı talaş ve yiğinti katmani oluşumu üzerine etkisi” Politeknik Dergisi, vol. 18, pp. 141-148, 2015.

[5] B. Şenol, Y. Turgut, “AL-5083 alaşiminin frezelenmesinde kesme kuvveti, yüzey pürüzlülüğü ve çapak yüksekliğinin optimizasyonu" 7 th International Symposium on Machining, November, 2016, Marmara University, Istanbul, pp. 24-34.

[6] B. Akyüz, S. Şenaysoy, “Alüminyum alaşimlarinda yaşlandirma işleminin mekanik özellikler ve işlenebilirlik üzerindeki etkisi" Bilecik Şeyh Edebali Üniversitesi Fen Bilimleri Dergisi, vol.1, pp. 1-9, 2014.

[7] A.Saravanakumar, S.C.Karthikeyan, B.Dhamotharan, V.G. Kumar, "Optimization of CNC turning parameters on aluminum alloy 6063 using Taguchi robust design" Materials Today: Proceedings, vol. 5, pp. 8290-8298, 2018. doi: https://doi.org/10.1016/j.matpr.2017.11.520

[8] S.P. Palaniappan, K. Muthukumar, R.V. Sabariraj, $\mathrm{S}$. Dinesh Kumar, T. Sathish, "CNC turning process parameters optimization on Aluminium 6082 alloyby using Taguchi and ANOVA" Materials Today: Proceedings, vol. 21, pp. 1013-1021, 2020. doi https://doi.org/10.1016/j.matpr.2019.10.053

[9] H. Gürbüz, F. Sönmez, Ş. Baday, U. Şeker, "Farkl1 talaş kirici formlarinin esas kesme kuvvetlerine etkisinin matematiksel modellenmesi" Batman Üniversitesi Yaşam Bilimleri Dergisi, vol. 8, pp. 1321, 2018.

[10] B. Özlü, H. Demir, E. Nas, “ CNC tornalama işleminde yüzey pürüzlülüğü ve kesme kuvvetlerine etki eden parametrelerin matematiksel olarak modellenmesi" İleri Teknoloji Bilimleri Dergisi, vol. 3, pp. 75-86, 2014.

[11] C.V. Ajay, V.Vinoth, "Experimental optimization of cutting parameters in turning of brassalloy using Taguchi method" Materials Today: Proceedings Today, pp. 1-7, 2020. doi: https://doi.org/10.1016/j.matpr.2020.09.561

[12] R. A. Mali, M. D. Agrahari, T.V.K. Gupta, "FE based simulation and experimental validation of forces in dry turning of aluminium 7075" Materials Today: Proceedings, vol. 27,pp. 2319-2323, 2020. doi: https://doi.org/10.1016/j.matpr.2019.09.120 
[13] A. Çakır, A. Duran, U. Şeker, "The Effect of different cooling methods to hole quality and tool life in the drilling of AA7075 and AA2024 aluminum alloys" Manufacturing Technologies and Applications, vol. 1, pp. 1-13, 2020.

[14] A. Çakır Şencan, S. Yağmur, N. Kavak, G. Küçüktürk, U. Şeker, "The effect of minimum quantity lubrication under different parameters in the turning of AA7075 and AA2024 aluminium alloys", The International Journal of Advanced Manufacturing Technology, vol. 84, pp. 2515-2521, 2016. doi: https://doi.org/10.1007/s00170-015-78784.

[15] D. B. Cönger, U. Emiroğlu, A. Uysal, E. Altan, "Alüminyum 6061 malzemenin MQL yöntemi ile frezelenmesinde nano MoS2 katkili kesme sivisi kullaniminin kesme kuvvetleri ve yüzey pürüzlülüğüne etkilerinin incelenmesi” Makina Tasarım ve Imalat Dergisi, vol. 17, pp. 31-37, 2019.

[16] S. A. Yaşar, G. Uzun, İ. Korkut, "17-4 PH ve 15$5 \mathrm{PH}$ paslanmaz çeliklerinin tornalanmasında kesme parametrelerinin kesme kuvveti ve yüzey pürüzlülüğüne etkilerinin araştırılması" Karaelmas Fen ve Mühendislik Dergisi, vol. 10, pp. 71-81, 2020.

[17] B. Yılmaz, Ş. Karabulut, A. Güllü, "Performance analysis of new external chip breaker for efficient machining of Inconel 718 and optimization of the cutting parameters" Journal of Manufacturing Processes, vol. 32, pp. 553-563, 2018. doi: https://doi.org/10.1016/j.jmapro.2018.03.025.

[18] H. Gürbüz, A. Kurt, İ. Korkut, U.Şeker, "The experimental investigation of the effects of different chip breaker forms on the cutting forces" Advanced Materials Research, vol 23, pp. 191-194, 2007.

[19] H. Gürbüz, A. Kurt, U.Şeker," Investigation of the effects of different chip breaker forms on the cutting force using artificial neural networks" Gazi University Journal of Science, vol. 25, pp. 803-814, 2012.

[20] Ö. Tekaslan, N. Gerger, M. Günay, U. Şeker, "AISI 304 östenitik paslanmaz çeliklerin titanyum karbür kaplamalı kesici takım ile tornalama işleminde kesme kuvvetlerinin incelenmesi" Pamukkale Üniversitesi Mühendislik Bilimleri Dergisi, vol. 13, pp. 135-144, 2011.

[21] A. Turhan, "Tornalama işleminde kesme parametrelerinin ve iş parçası uzunluğunun geometrik toleranslara etkilerinin incelenmesi" Yüksek Lisans Tezi, Marmara Üniversitesi, İstanbul, Türkiye, 2008.
[22] P. Chandra, ,C. P. Rao, R. Kiran, V. R. Kumar "Influence of machining parameter on cutting force and surface roughness while turning alloy steel". Materials Today: Proceedings: vol. 5, pp. 1179411801, 2018.

doi: https://doi.org/10.1016/j.matpr.2018.02.149

[23] S. Yağmur, A. ACIR, U. Şeker, M. Günay, "Delik delme işlemlerinde kesme parametrelerinin kesme bölgesindeki sıcaklığa etkisinin deneysel incelenmesi" Gazi Üniversitesi MühendislikMimarlık Fakültesi Dergisi, vol. 28, pp. 1-6, 2013.

[24] T. Meral, M. Günay "Kaplamalı ve kaplamasız karbür matkap ile ferritik paslanmaz çeliğin delinebilirlik analizi" Gazi Mühendislik Bilimleri Dergisi, vol. 5, pp.159-166, 2019.

[25] H. Gökçe, M. Yavuz, H. Gökçe, U. Şeker "Orjinal matkap geometrisinde delme performansının sonlu elemanlar yöntemi ile doğrulanması" Gazi Mühendislik Bilimleri Dergisi, vol. 3, pp.27-34, 2017.

[26] M. E. Korkmaz, T. Meral, M. Günay “AISI 420 martenzitik paslanmaz çeliğin delinebilirliğinin sonlu elemanlar yöntemiyle analizi" Gazi Mühendislik Bilimleri Dergisi, vol. 4, pp.223-229, 2018.

[27] K. Gök, M. Erdem, A. Gök, “AISI 1006 çeliğinin tornalama sürecinde kesici takım uç yarıçapının kesme sıcaklığı ve kesme kuvveti üzerindeki etkisinin numerik olarak incelenmesi" TÜBAV Bilim Dergisi, vol. 4, pp.1-8, 2010.

[28] A. Uysal, E. Altan, "Experimental investigation of cutting forces in orthogonal cutting using rounded edge worn tool" Journal of Engineering and Natural Sciences, vol. 31, pp. 350-362, 2013.

[29] K. Okushima, Y. Kakino, "Sudy on the Generating of Machined Surface", Bulletin of Japan Society of Mechanical Engineers, vol. 12, pp. 141-1, 19. 